\title{
Stabilization of Neem Oil Biodiesel with Corn Silk Extract during Long-term Storage
}

\author{
Rehab Farouk M. Ali ${ }^{1 *}$ and Ayman M. El-Anany ${ }^{2}$ \\ ${ }^{1}$ Department of Biochemistry, Faculty of Agriculture, Cairo University, 12613, Giza, EGYPT \\ ${ }^{2}$ Special Food \& Nutrition Department, Food Technology Research Institute; Agricultural Research Center, Giza, EGYPT
}

\begin{abstract}
The current study aimed to evaluate the antioxidant efficiency of different extracts of corn silk. In addition, the impact of corn silk extract on oxidative stability of neem biodiesel during storage was studied. The highest phenolics, DPPH radical scavenging and reducing power activities were recorded for methanolwater extract. The longest oxidation stability $(10 \mathrm{~h})$ was observed for biodiesel samples blended with 1000 ppm of corn silk extract (CSE). At the end of storage period the induction time of biodiesel samples mixed with $1000 \mathrm{ppm}$ of CSE or butylated hydroxytoluene (BHT) were about 6.72 and 5.63 times as high as in biodiesel samples without antioxidants. Biodiesel samples blended with 1000 ppm of CSE had the lowest acidity at the end of storage period. Peroxide value of biodiesel samples containing 1000 ppm of CSE was about 4.28 times as low as in control sample without antioxidants.
\end{abstract}

Key words: antioxidant efficiency, corn silk extract, oxidative stability, neem oil biodiesel, long-term storage, Rancimat

\section{Introduction}

Biodiesel has been mainly produced from vegetable oils all over the world. More than 95\% of global biodiesel production is made from vegetable oils ${ }^{1)}$. Between 2005 and 2017 , biodiesel use of edible vegetable oils is expected to represent more than a third of the projected growth in edible vegetable oil use ${ }^{2)}$. However, there are several reasons against the use of edible vegetable oils as a feedstock in biodiesel production.

Utilization edible oil in the production of biodiesel fuel has an impact on global imbalances and market demand and food supply by high prices, and limit the food sources and the growth of a commercial plant capability. Consequently, focus should be turned to resources of non-edible, which are not widely used in human nutrition and can grow in arid lands. Oils from these resources are, as a rule, unsuitable for human consumption due to the presence of toxic compounds. For example, the main toxic compounds in jatropha plants are protein curcin and purgative agents; protein ricin in castor plant ${ }^{1)}$.

Neem (Azadirachta indica), which belongs to the family Meliaceae, is an evergreen tree of potential medicinal value and typically found in most tropical countries of the world. In the recent period, it was planted nearly 4,000 neem tress in Egypt found in the Delta zone and South Sinai Governorate ${ }^{3)}$. The adult of neem tree produces about $350 \mathrm{~kg}$ of fruits and this amount is given about $30 \mathrm{~kg}$ of seeds ${ }^{4)}$. Neem kernels contain $30-50 \%$ oil and many active ingredients having antifeedant, growth-inhibiting, antiviral activity and anti-ovipositional properties ${ }^{5,6)}$. Neem oil is widely used as insecticides, lubricant, drugs for variety of diseases such as diabetes and tuberculosis ${ }^{7-9}$. Average percent of fatty acid content was oleic acid $45.6 \%$, linoleic acid $16.8 \%$, palmitic acid $17.21 \%$, stearic acid $15.2 \%$, and linolenic acid $1.3 \%{ }^{10)}$.

Biodiesel composes of long chain fatty acid esters derived from feed stocks such as animal lipid, vegetable oils, as well as used cooking oil, etc. which contain saturated and unsaturated fatty acids which are highly susceptible to oxidation accelerated by exposure to air during storage and at high temperature can result in production of polymerized compounds. Oxidation instability may lead to produce the oxidation products such as aldehydes, shorter chain carboxylic acids, insolubles as well as sediments in the biodiesel ${ }^{11)}$. The oxidation products formed can cause damage to the mechanical parts of engines, such as corrosion of the metal systems, degradation of the physical characteristics of the elastomers, and blockages in the injection pumps and filters ${ }^{12,13)}$. Antioxidant substances scavenge free radical molecules therefore, stabilizing fatty peroxyl radicals and slowing oxidation chain reactions ${ }^{14-17)}$. Phenolic substrates are commonly found in both edible and

*Correspondence to: Rehab Farouk M. Ali, Department of Biochemistry, Faculty of Agriculture, Cairo University, 12613, Giza, EGYPT

E-mail: malkelanany@gmail.com

Accepted September 13, 2016 (received for review July 23, 2016)

Journal of Oleo Science ISSN 1345-8957 print / ISSN 1347-3352 online

http://www.jstage.jst.go.jp/browse/jos/ http://mc.manusriptcentral.com/jjocs 
non edible plants, and they have been showed to have multiple impacts, including antioxidant activity ${ }^{18)}$. Potential sources of antioxidant compounds have been searched in several types of plant substrates such as vegetables, fruits, leaves, oilseeds, cereal crops, barks and roots, spices and herbs, and crude plant drugs ${ }^{19)}$.

Corn is the world's third most important cereal crop, less than wheat and rice ${ }^{20)}$. Corn silk, the female flower stigma of maize (Zea mays L.) is a yellow silky strand which is on top of corn fruit. Corn silk is a by-product obtained from maize production e.g. food, processed food and feeds. Silk of corn is discarded as waste along with the other parts of the corn like cobs as well as husk because of a lack of benefits of them. Corn silk consists of protein, carbohydrate, $\mathrm{Ca}^{2+}, \mathrm{K}^{+}, \mathrm{Mg}^{2+}$ and $\mathrm{Na}^{+}$salts, volatile oils, steroids, alkaloids as well as some of flavonoids ${ }^{21-23)}$. Several components present in corn silk have been reported to possess antioxidant activities ${ }^{24)}$. Corn $\operatorname{silk}(Z e a$ mays) is traditionally used in the treatment of cystitis, edema, gout, kidney stones, nephritis, and urological disorders ${ }^{23)}$.

The primary aim of the current study is to assess the antioxidant efficiency of different extracts of corn silk (Zea mays hairs). Furthermore, the impact of corn silk extract on oxidative stability of neem seeds oil based biodiesel during long-term storage was assessed.

\section{Materials and methods \\ 2.1 Materials}

Neem seeds used in the current investigation were harvested in July 2014 from a 15 year-old trees located at Giza, Egypt. The seeds were dried under shade. The dried seeds were ground in an electric grinder(Braun Model 1021), passed through a $150-\mu \mathrm{m}$ mesh sieve, and stored in plastic bags and stored in a freezer $\left(-25^{\circ} \mathrm{C}\right)$ until further use.

Corn silk was collected from Agricultural Research Center, Giza, Egypt. Corn silk was detached, cleaned and washed with distilled water. The collected corn silk was dried in an electric air draught oven (Isotemp Oven, Fisher Scientific) at $50^{\circ} \mathrm{C}$ for 24 hours. The dried corn silk was ground in an electric grinder(Braun Model 1021) and stored in glass containers at $4{ }^{\circ} \mathrm{C}$ for further analysis.

Folin-Ciocalteu reagent, sodium carbonate, citric acid, aluminum chloride, ferric chloride, copper sulfate, tween 80 and Butylated hydroxytoluene (BHT) were purchased from Sigma Chemical Co., Ltd (St. Louis, MO, USA).

\subsection{Extraction of Antioxidant Material}

The ground corn silk materials (100 g) were separately mixed with $1000 \mathrm{~mL}$ of each of the extraction solvents, $100 \%$ methanol, $80 \%$ methanol (methanol: water, 80:20 v/ v), $100 \%$ acetone, $80 \%$ acetone (acetone : water, 80:20 v/ v) and distilled water in conical flasks. Extraction was exe- cuted on a shaker for $48 \mathrm{~h}$. Each extract was filtered through Whatman No 1 paper. The collected filtrates were individually dried at $45^{\circ} \mathrm{C}$ by using a rotary evaporator. The concentrated extracts were stored in kept at $-18^{\circ} \mathrm{C}$ until further use.

\subsection{Neem oil extraction}

The extraction of oil of neem seeds was carried out by using chloroform: methanol (2:1, v: v) according to the procedures proposed by Bligh and Dyer ${ }^{25)}$.

\subsection{Purification of neem oil}

Purification process was performed to improve the quality attributes (i.e., free fatty acid content, peroxide value) of crude oil. Magnesol XL was added to crude neem oil at level of $2 \%(\mathrm{w} / \mathrm{v})$ then mechanically stirred for $1 \mathrm{~h}$ at $105^{\circ} \mathrm{C}$. The slurry was filtered through a Whatman No. 1 filter paper using vacuum filtration. The vacuum filtration facilitates the oil flow through the filter paper ${ }^{26)}$. Filtrated neem oil was heated at $70^{\circ} \mathrm{C}$ and hot water $80-85^{\circ} \mathrm{C}$ was $\operatorname{added}(1: 1 \mathrm{v} / \mathrm{v})$. The mixture has been mixed using rod of glass for 15 minutes, and left for cooling at room temperature. The upper oil phase was centrifuged at 10,000 rpm for $20 \mathrm{~min}$. The centrifuged oil was stirred with the anhydrous sodium sulfate for ca. $5 \mathrm{~min}$, and then filtered (vacuum filtration) through a Whatman No 1 paper $^{27)}$.

\subsection{Biodiesel production}

One thousand grams of purified neem oil were placed into a $2000 \mathrm{~mL}$ round-bottom flask equipped with a condenser. After the oil was heated to $65^{\circ} \mathrm{C}$, the solution of sodium hydroxide $(5.0 \mathrm{~g})$ in methanol ( $144.82 \mathrm{~mL}, 6: 1$ molar ratio of methanol to oil) was slowly added into the reaction. The reaction temperature of the transesterification treatment was appointed at $60^{\circ} \mathrm{C}$. The reaction continued for $110 \mathrm{~min}$. By the end of the incubation, the mixture was transferred into a reparatory funnel, left for $24 \mathrm{~h}$ for separation the glycerin and impurities from the biodiesel. The produced biodiesel was washed with deionized hot water $\left(50^{\circ} \mathrm{C}\right)$ several times for removing the catalyst, glycerol, and impurities ${ }^{28)}$.

\subsection{Storage experiment}

The obtained biodiesel sample has been divided into 5 groups each one $200 \mathrm{~mL}$, the first one represents the control, without additives. The second and third portions were blended with 500 and 1000 ppm of BHT. The fourth and the last portion were blended with corn silk extracts at levels of 500 and 1000 ppm, respectively. Biodiesel samples have been stored at room temperature of approximately $25^{\circ} \mathrm{C}$ and relative humidity $65 \%$ in a $100 \mathrm{~mL}$ glass bottle and were tightened with a cap to ensure that the biodiesel samples were free from air contact ${ }^{29)}$. Biodiesel samples were evaluated and analyzed by using various procedures 
at the start of the experiment and at 1, 2, 3, 4, 5 and 6 months from the start of the experiment.

\subsection{Analytical methods}

\subsubsection{Determination of total phenolic content}

The total phenolic content was assayed by using FolinCiocalteu reagents with analytical grade gallic acid as the standard. $1 \mathrm{~mL}$ of extract or standard solution $(0-500 \mathrm{mg} /$ $\mathrm{L})$ was added to deionized water $(10 \mathrm{~mL})$ and Folin-Ciocalteu phenol reagents $(1.0 \mathrm{~mL})$. After 5 minutes, $20 \%$ sodium carbonate $(2.0 \mathrm{~mL})$ has been added to the mixture. After being kept in darkness for $1 \mathrm{~h}$, the absorbance was measured at $750 \mathrm{~nm}$. Amounts of total phenolics were calculated using gallic acid calibration curve. The results were expressed as mg of gallic acid equivalent per $100 \mathrm{~g}$ dry weight $(\mathrm{DW})^{30)}$.

2.7.2 Determination of Individual Phenolic Compounds by HPLC

Phenolic compounds of methanolic extract of corn silk were quantified using the previously reported procedures by Ahmed and $\mathrm{Ali}^{31)}$.

2.7.3 Antioxidant activity

a. Scavenging DPPH radicals

The free radical scavenging capacity of different extracts of corn silk was determined by using 1, 1-diphenyl-picrylhydrazil (DPPH) assay ${ }^{32)}$. Butylated hydroxytoluene(BHT) was used as positive control. The radical-scavenging activity was expressed as inhibition percentage and calculated using the following equation:

\% Radical scavenging activity $=[($ Abs control - Abs test) $/($ Abs control) $] \times 100$.

Where, Abs control is the absorbance of DPPH radical + methanol.

Abs sample is the absorbance of DPPH radical + sample extract or standard.

b. Reducing power assay

The reducing power of the extracts was conducted according to previously reported procedures by Chou et $a l^{33)} .1 \mathrm{~mL}$ of extract was mixed with $2.5 \mathrm{~mL}$ of phosphate buffer $(0.2 \mathrm{M}, \mathrm{pH} 6.6)$ and and potassium ferricyanide $\left[\mathrm{K}_{3} \mathrm{Fe}\right.$ $\left.(\mathrm{CN})_{6}\right](2.5 \mathrm{~mL}, 1 \%)$. After incubation at $50^{\circ} \mathrm{C}$ for $25 \mathrm{~min}$., $2.5 \mathrm{~mL}$ of trichloroacetic acid $(10 \mathrm{~g} / 100 \mathrm{~mL})$ were added and the mixture was centrifuged at $650 \mathrm{rpm}$ for $10 \mathrm{~min}$. Finally, $2.5 \mathrm{~mL}$ of the upper layer was mixed with $2.5 \mathrm{~mL}$ of deionized water and $0.5 \mathrm{~mL}$ of aqueous $\mathrm{FeCl}_{3}(0.1 \mathrm{~g} / 100$ $\mathrm{mL}$ ). The absorbance was measured at $700 \mathrm{~nm}$. Higher absorbance indicates higher reducing power. Butylated hydroxytoluene (BHT) was used as positive control.

\subsubsection{Moisture content}

The amount of moisture was determined according to the AOAC official method ${ }^{34)}$.

\subsubsection{Density}

The density of the samples was determined by a mass over volume measurement at $25^{\circ} \mathrm{C}$.

2.7.6 Acid value

Acid value was determined according the A.O.A.C. $\operatorname{method}(969.17)^{35)}$. Acid value is expressed as $\mathrm{mg} \mathrm{KOH}$ required to neutralize one gram of sample.

\subsubsection{Peroxide value}

Determination of peroxide value was performed according to the procedures of A.O.A.C method $(965.33)^{35)}$. Peroxide value is expressed as milliequivalent peroxides $\mathrm{kg}^{-1}$ oil sample.

2.7.8 Oxidative stability of biodiesel samples

The oxidative stability of the biodiesel samples was evaluated using Rancimat 679 instrument(Metrohm, Herisau, Switzerland). Essentially, the oxidation process happens inside a reaction vessel heated at $110^{\circ} \mathrm{C}$ (with $3 \mathrm{~g}$ of biodiesel sample) under air flow of $10 \mathrm{~L} \mathrm{~h}^{-1}$. The volatiles oxidation products formed during the oxidation experiment are collected in a vessel containing $60 \mathrm{~mL}$ of distillated water, and the water conductivity is monitored continuously. A sudden change in electric conductivity of this water is noticed in the induction period point, indicating the propagation launch of an oxidation process.

\subsection{Statistical analysis}

Results are expressed as mean \pm SD. Data were statistically analyzed according to the procedures described by Gomez and Gomez ${ }^{36)}$. SPSS Version 18.0 (SPSS Inc., Chicago, IL, USA) was used to analyze data.

\section{Results and discussion}

\subsection{Total phenolic compounds (TPCs) of different solvent extracts of corn silk}

Phenolic compounds are a class of antioxidant agents acting as free radical terminators ${ }^{37)}$. Phenolic substances have been shown to be responsible for the antioxidant activity of plant materials. TPC may contribute directly to antioxidative activity ${ }^{38)}$ of the plant extracts. Figure 1 shows the total phenolic compounds of different solvent extracts of corn silk. TPCs of corn silk extracts ranged from 274.81 to $510.60 \mathrm{mg} / 100 \mathrm{~g}$ dry material(DW). Similar results were reported by Tian et $a l^{39)}$, who studied the contents of total phenolic of six corn silk varieties (Denghai6702, Delinong988, Tunyu808, Zhongdan909, Liangyu208, and Jingke968). They showed that the highest content of total phenolics was detected in Zhongdan909 $\left(4.87 \mathrm{mg} \mathrm{g}^{-1}\right)$, whereas the lowest content was found in Liangyu208(1.99 $\left.\mathrm{mg} \mathrm{g}^{-1}\right)$. Solvents, such as methanol, ethanol, acetone, ethyl acetate, and their combinations were used for the extraction of phenolics from plant substratces, often with various levels of water. Selecting the right solvent affects 


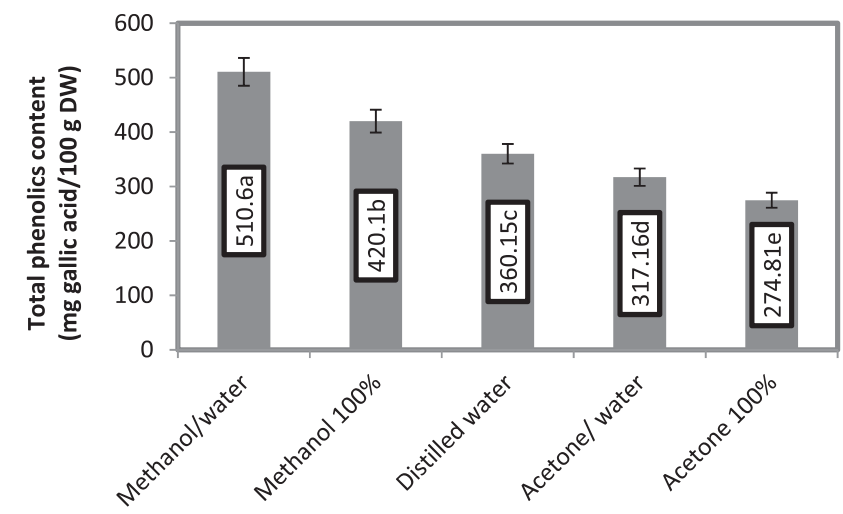

Fig. 1 Total phenolic content of different solvent extracts of corn silk (LSD at $0.05=0.47)$.

Data are expressed as mean $\pm \mathrm{SD}$.

Values given represent means of three determinations. Values followed by different letters are significantly different $(p<0.05)$.

the amount and rate of polyphenols extracted ${ }^{40)}$. There are significant effects of various solvents on the TPC $(p<0.05)$. The highest $(p \leq 0.05)$ levels of TPC $(510.60 \mathrm{mg} / 100 \mathrm{~g} \mathrm{DW})$ were recorded for methanol-water $(80: 20 \mathrm{v} / \mathrm{v})$ extract followed by pure methanol extract (420.10 mg / 100 g DW) and distilled water extract (360.15 mg / $100 \mathrm{~g} \mathrm{DW}$ ). The variability in the TPC caused by different solvents may be attributed to the varying solubility of the phenolic compounds, which is directly related to the compatibility of the compounds with the solvent system ${ }^{41)}$. Mixtures of alcohols and water at different levels have shown to be more effective in extracting phenolic compounds compared to monocomponent solvent system ${ }^{42)}$. Mixing a small quantity of water with organic solvent usually leads to a more polar medium, which facilitates the polyphenols extraction ${ }^{43)}$. In addition, the mixture viscosity decreased because of the presence of water, which might have improved the mass transfer ${ }^{44)}$. Similar, observations were noted by Agbangnan et $a l .{ }^{45)}$, who found that the high yield of phenolics can be extracted from sorghum leaf using water, while extraction of phenolics from wheat bran requires $80 \%$ aqueous ethanol $^{46)}$. However, moderate amounts (317.16 and 274.81) of TPCs were detected for $80 \%$ acetone (acetone: water, $80: 20 \mathrm{v} / \mathrm{v}$ ) and $100 \%$ acetone, respectively. The type of phenolics soluble in each of the extracting solutions tested is mainly different, because the phenolics include one or more of hydroxyl groups (polar side) attached directly to an aromatic ring (non polar side). This stereochemistry differentiates phenolics according to their polarity variance, which affects the recovery of phenol from natural sources, when accomplished with solvent extraction, being the yield of the process depends strongly on the nature of the solvent ${ }^{47)}$. In particular, methanol alcohol has been demonstrated to be more efficient in extraction of polyphenols with lower molecular weight while flavones with the higher molecular weight are better extracted with aqueous acetone ${ }^{4-50)}$. Acetone has also been found to be more efficient than other organic solvents for the extraction of phenolics from different raw materials such as brewer's spent grains ${ }^{47)}$, Syzygium cumini ${ }^{51)}$ Acetone: water mixtures $(50-95 \% \mathrm{v} / \mathrm{v})$ have been reported to be one of the most effective solvents for extraction of phenolics from different natural sources, especially from protein matrices, since this mixture is able to degrade polyphenol-protein complexes $^{52)}$. These differences could be attributed to the different methods of extraction and standards used, but also to different varieties, genomics and harvest season of the samples (all these parameter affect the synthesis and accumulation of phenolics in some parts of the plant $)^{41,53)}$. In the present investigation, the higher phenolics content of aqueous methanol ( $80 \%$ methanol) extract might be responsible for the enhanced antioxidative activities compared to the other extracts. Similar studies reported that the enrichment of phenolic compounds within plant extracts is correlated with their enhanced antioxidant activi$\mathrm{ty}^{54-56)}$.

\subsection{Antioxidant activity}

An antioxidant may be defined as a substance which, in relatively low concentration, markedly inhibits the rate of the reaction with oxygen ${ }^{57,58)}$. The stable free radical $\alpha$, $\alpha$-diphenyl- $\beta$-picrylhydrazyl (DPPH) assay is rapid and sensitive way to survey the antioxidant activity of plant extracts $^{23)}$. The radical scavenging activity of different extracts of corn silk was compared with that of BHT at the same concentration and expressed as\% of inhibition against DPPH(Fig. 2). All extracts of corn silk exhibited appreciable scavenging activity ranging from 53.24\% to 83.7\% (Fig. 2). Free radical scavenging activities of extracts depends mainly on the structural configuration of these compounds and the capacity of these components to lose hydrogen ${ }^{59,60)}$. Aqueous methanol (80\%) extract of corn silk has significantly higher DPPH radical scavenging activities than those from other extracts and greater than BHT. The highest DPPH radical scavenging activities (83.7\%) was observed for aqueous methanol (80\%) extract of corn silk followed by $\operatorname{BHT}(78.1 \%)$, pure methanol extract $(74.9 \%)$ and water extract $(71.02 \%)$. Aqueous acetone (acetone: water, 80:20 v/v) and 100\% acetone showed weaker DPPH radical scavenging activities (59.3 and $53.24 \%$, respectively) than methanolic extract. The different antioxidant activities of phenolic extracts could be attributed to different extracting solvents, as the antioxidant activity depended mainly on polarity and the type of the solvent, the procedures of isolation, the purity of active components and the method of determination ${ }^{61)}$. Interestingly, Sultana et $a l .{ }^{62)}$ showed that among the four solvent extracts [ethanol, methanol, aqueous ethanol (ethanol: water, 80:20 v/v) and aqueous methanol (metha- 


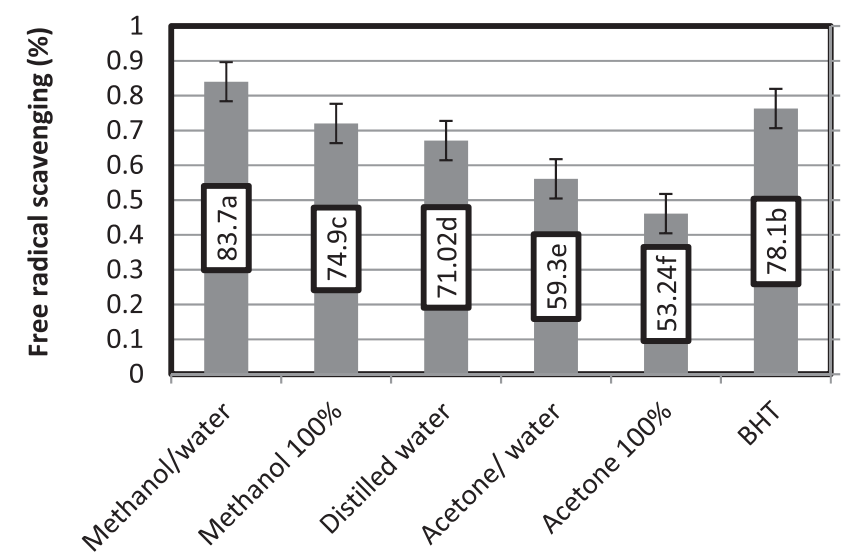

Fig. 2 DPPH free radicals scavenging activity of different extracts of corn silk compared to BHT (LSD at 0.05 $=0.49$ ).

Data are expressed as mean \pm SD.

Values given represent means of three determinations. Values followed by different letters are significantly different $(p<0.05)$.

nol: water, 80:20 v/v) ]used, the aqueous methanol and aqueous ethanol extracts had the greatest phenolic content. This might be attributed to the fact that phenolics have been extracted in larger quantities with more polar solvents such as aqueous ethanol / methanol as compared to absolute ethanol / methanol ${ }^{63,64)}$. The results of Tomsone et $a l .{ }^{65)}$, on horseradish roots showed that that acetone comparing to other solvents is an acceptable solvent, however it is not the best. The reducing power assay is usually used to evaluate the ability of an antioxidant to donate an electron ${ }^{66)}$. The presence of reductants in samples leads to reduce the ferric ion/ferricyanide complex to its ferrous form. The amount of ferrous ion complex can then be monitored by measuring the formation of Perl's Prussian blue at $700 \mathrm{~nm}^{41)}$. Results of reducing power activity of different solvent extracts of corn silk are presented in Fig 3. The reducing power of corn silk extracts ranged from 0.46 to 0.840 (absorbance value). The order of reducing power of the extracts is aqueous methanol $(80 \%)>$ pure methanol extract $>$ water extract $>$ aqueous acetone extract $>100 \%$ acetone extract. In the same time the reducing power activity of aqueous methanol $(0.840$, absorbance value) was higher than that of $\operatorname{BHT}(0.763$, absorbance value) at the same concentration. The reducing power of certain compounds is associated with the presence of reductones $\left.{ }^{67}{ }^{68}\right)$. The antioxidant action of reductones is based on the breaking of the free-radical chain by donating a hydrogen atom ${ }^{69)}$.

These findings indicate that the aqueous methanol (80\%) extract of corn silk possessed greater phenolic content, DPPH radical scavenging activity and reducing power activity than those from other extracts and BHT. Thus, the stabilization effects of aqueous methanol (80\%)

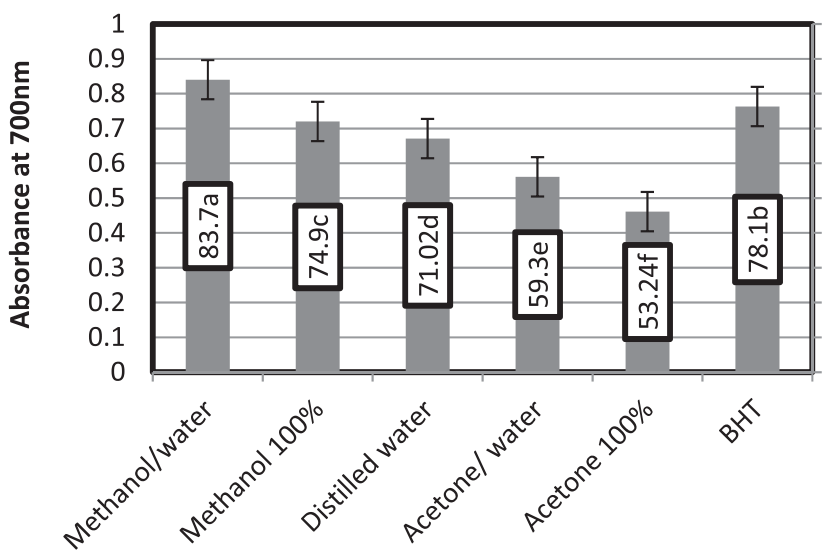

Fig. 3 Reducing power activity of different solvent extracts of corn silk compard to BHT (LSD at 0.05 $=0.01$ ).

Data are expressed as mean \pm SD.

Values given represent means of three determinations. Values followed by different letters are significantly different $(p<0.05)$.

extract were evaluated by mixing different levels of this extract into neem biodiesel during long storage process.

\subsection{Qualitative analysis of Phenolic compounds in metha- nolic extract of corn silk}

Based on the abovementioned results, HPLC analysis was employed to define qualitative and quantitative content of phenolic acids in methanolic extract of corn silk. HPLC is the preferred technique for quantification of phenolic compounds ${ }^{70}$. Several polyphenolic compounds were identified in methanolic extract of corn silk. These included gallic, pyrogallol, catechin, protocatechuic acid, catechol, chlorogenic acid, rutin, caffeic acid, vanillic acid, quercetin, ferulic acid, coumaric acid, cinnamic, and kaempferol (Table 1). The quantities of the identified compounds are expressed in milligrams per $100 \mathrm{~g}$ of dry sample. The predominant phenolics of aqueous-methanolic extract of corn silk are protocatechuic acid(178.5), chlorogenic acid (26.71), gallic acid (12.5) pyrogallol (11.7), vanillic acid (10.52), coumaric acid (7.92), kaempferol (15.32) and ferulic acid (5.90) mg/100 g DW, respectively (Table 1). These findings in agreement with previous studies showed that protocatechuic, gallic, cinnamic, $p$-coumaric acids are the most representative phenolic acids in the phenolic composition of corn silk extracts ${ }^{71-73)}$.

\subsection{Physicochemical properties of neem biodiesel}

The physicochemical properties of the biodiesel obtained from neem seeds oil were shown in Table 2. The moisture content of fresh neem oil biodiesel was $0.05 \%$, this low level of moisture content reflects the quality of the obtained biodiesel. The greatest level of water content allowed in biodiesel as defined in the ASTM standard 
Table.1 HPLC analysis of phenolic compounds (mg / $100 \mathrm{~g}$ DW) of methanolic extract of corn silk.

\begin{tabular}{cc}
\hline $\begin{array}{c}\text { Phenolic compounds } \\
(\mathrm{mg} / 100 \mathrm{~g})\end{array}$ & Corn silk extract \\
\hline Gallic & 12.5 \\
Pyrogallol & 11.7 \\
Catechin & 2.01 \\
Protocatechuic & 178.5 \\
Catechol & 2.85 \\
Chlorogenic acid & 26.71 \\
Rosmarinic acid & $\mathrm{ND}$ \\
Rutin & 1.37 \\
Caffeic acid & 0.87 \\
Vanillic acid & 10.52 \\
ferulic acid & 5.90 \\
Coumaric acid & 7.92 \\
Cinnamic & 0.78 \\
Kaempferol & 15.32 \\
\hline
\end{tabular}

Values are presented as mean value $(n=2)$ and expressed as $\mathrm{mg} / 100 \mathrm{~g}$ of dry weight.

ND means not detected.

D6751 is $0.050 \%$ vol $^{74)}$. High moisture content in biodiesel may cause problems in handling, transportation, and storage $^{75)}$. Density is an important characteristic of fuel, because the injection systems, pumps, as well as injectors must provide the amount of fuel specifically adjusted to provide proper combustion ${ }^{76}$. Density of the obtained biodiesel was $0.868 \mathrm{~g} \mathrm{~cm}^{-3}$. This value satisfies the value of the density identified by the American Society for Testing and Materials (ASTM D6751) and European standard (EN 14214). The induction period of fresh neem oil biodiesel without adding any antioxidants was $5.2 \mathrm{~h}$. ASTM D675107 includes an oxidation stability standard of a three-hour minimum induction period (IP) as measured using the Rancimat test $(\mathrm{EN} 14112)^{77}$. The European Committee for standardization adopted a six-hour minimum IP as the specification $^{78)}$. The acid value is a facile method for monitoring fuel quality. Acid value of neem oil biodiesel was 0.17 $\mathrm{mg} \mathrm{KOH} / \mathrm{g}$. The greatest value of $\mathrm{AV}$ for pure biodiesel, as identified in ASTM standard D6751 is $0.8 \mathrm{mgKOH} / \mathrm{g}^{74)}$. However EN $14112^{78)}$ sets a limit of acid value $0.58 \mathrm{mg}$ $\mathrm{KOH} / \mathrm{g}$ for biodiesel. The peroxide value measures the presence and amount of unstable hydroperoxide which is a portion of deteriorated biodiesel formed when oxygen of the air react with fatty esters (oxygenated fatty esters), in other word it measures how much oxygen is incorporated into biodiesels chemical make up as oxygenated fatty compounds. These oxygenated fatty compounds are inherently unstable, thus it is usually the first step in the oxidative degradation pathway of biodiesel fuel. Peroxide value of fresh neem oil biodiesel was 2.4 millieguivalent peroxides/ $\mathrm{kg}$ (Table 2). The iodine number is an index of the number of double bonds in biodiesel, and therefore is a parameter that quantifies the degree of unsaturation of biodiese $\mathrm{l}^{26}$. Iodine value of fresh neem oil biodiesel is $71.9 \mathrm{~g} \mathrm{I}_{2} / 100 \mathrm{~g}$. The European EN 14214 biodiesel standard sets a limit for iodine value of $<120$. These findings indicate that the density, moisture content, acid value, iodine number, and oxidation stability at $110^{\circ} \mathrm{C}$ of the biodiesel obtained from neem seeds oil agree with the approved international standards.

\subsection{Effect of antioxidants on the oxidative stability of neem oil biodiesel}

Oxidative stability is one of the main issues that affect the use of biodiesel because of its content of esters of linoleic and linolenic acids, which methylene bis allylic positions are particularly susceptible to oxidation. Rancimat

Table 2 Physicochemical properties of the obtained biodiesel compared to ASTM and EN 14214 standards.

\begin{tabular}{lccc}
\hline \multicolumn{1}{c}{ Properties } & Values & $\begin{array}{c}\text { ASTM } \\
\text { specification }\end{array}$ & EN 14214 \\
\hline moisture content $\%$ & 0.05 & 0.05 maxmum & - \\
Density $\left(\mathrm{g} \mathrm{cm}^{-3}\right)$. & 0.868 & 0.87 to 0.90 & 0.86 to 0.90 \\
Acid value $\mathrm{mg} \mathrm{KOH} / \mathrm{g}$ & 0.17 & maxmum 0.8 & maxmum 0.50 \\
Iodine value $\left(\mathrm{g} \mathrm{I}_{2} / 100 \mathrm{~g}\right)$ & 71.9 & - & 120 maxmum \\
Oxidation Stability $110^{\circ} \mathrm{C}$ (hours) & 5.2 & minimum 3 & minimum 6 \\
peroxide value (milliequivalent peroxides $/ \mathrm{kg})$ & 2.4 & - & - \\
Physical state at $25^{\circ} \mathrm{C}$ & Liquid & & \\
\hline
\end{tabular}

Data are expressed as mean \pm SD.

Values given represent means of three determinations. 
method, described in EN 14112, has been included in the European biodiesel standards. It is nearly identical to the AOCS Oil Stability Index (OSI) method Cd12b-92 ${ }^{34)}$. As shown in Table 2, the oxidation stability of fresh biodiesel was $5.2 \mathrm{~h}$, this finding indicates that biodiesel sample met the standard ASTM D6751 (3 h) specification, however do not meet the EN 14214 (6 h) specification., which making it necessary to add antioxidants to the biodiesel samples to satisfy the quality specification for oxidation stability. Figure 4 shows the effect of two different antioxidants (BHT and corn silk extract) with concentrations of 500 and 1000 ppm, on the oxidation stability of neem biodiesel. In general, all of the tested additives had positive influence on the oxidation stability of biodiesel samples produced from neem oil and increased the induction time of samples. The increase of oxidation stability was gradually increased with increasing the concentration of antioxidant. The extension of IP by adding an antioxidant has been associated with the efficiency of antioxidant, which is sometimes called antioxidant index or protection factor. The oxidation stability of biodiesel samples blended with tested antioxidants varied from 7.6 to $10 \mathrm{~h}$. This finding indicates that the six-hour limit was reached when 500 ppm of corn silk extract or BHT were separately added at the same concentration. The longest oxidation stability (10h.) was observed for biodiesel samples blended with 1000 ppm of corn silk extract (CSE) followed by those samples treated with $1000 \mathrm{ppm}$ of $\operatorname{BHT}(9.3 \mathrm{~h})$, biodiesel sample blended with $500 \mathrm{ppm}$ of $\mathrm{CSE}(7.8 \mathrm{~h})$ and those samples mixed with BHT at concentration $500 \mathrm{ppm}(7.6 \mathrm{~h})$, respectively. These findings indicate that the extract of corn silk and BHT at level 1000 ppm improved the oxidation stability of the tested biodiesel by 92.30 and $78.84 \%$, respectively. Since the speed of oxidation of biodiesel depends upon factors i.e., temperature, light and intensity of radiation, studies should be conduct-

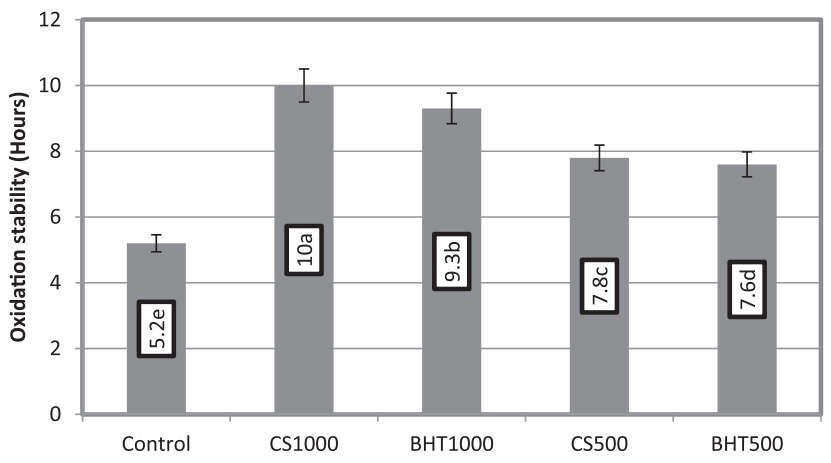

Fig. 4 Effect of two different antioxidants (BHT and corn silk extract) with concentration of 500 and 1000 ppm, on the oxidation stability of neem biodiesel. Data are expressed as mean $\pm \mathrm{SD}$.

Values given represent means of three determinations. Values followed by different letters are significantly different $(p<0.05)$. ed to determin an appropriate concentrations of antioxidants that can effectively provide long term storage stability of biodiesel and blends under various conditions ${ }^{79)}$. Phenol itself is chemically inert as an antioxidant. Hydrogen substitution by alkyl groups in ortho- and para-position increases the density of electron of the $\mathrm{OH}$ moiety by inductive effect. This reinforces its reactivity toward fat radicals. Furthermore, the basic structural orientation of the compounds identifies the antioxidant activity of phenolics, such as how easily a hydrogen atom from a hydroxyl group can be donated to a free radical, and the ability of the compounds to support an unpaired electron ${ }^{80)}$. The position of hydroxyl groups appears more important than their number for the antioxidant capacity of phenolics; for example, hydroxyl groups in the ortho position of the B ring can greatly enhance the antioxidant capacity, such as in catechins ${ }^{81)}$. Corn silk extract contains a large variety of phenolic derivatives, including protocatechuic, gallic, cinnamic, $p$-coumaric acids flavonoids, and tannins (Table 1). Protocatechuic acid and other structurally analogous dihydroxy and trihydroxyphenolic acids, 3,4-dihydroxyphenylacetic acid, hydrocaffeic acid, caffeic acid, gallic acid, 3,4,5-trihydroxyphenylacetic acid, and 3-(3,4,5-trihy droxyphenyl) propanoic acid show antioxidant activity by both chelating metal transition ions by scavenging free radicals through the donation of a hydrogen atom $(\mathrm{H} \cdot)$ or electron $\left(\mathrm{e}^{-}\right)^{82)}$. Phenolic acids also have a high antioxidant capacity, which decreases in the order: protocatechuic acid $>$ caffeic acid $>p$-hydroxybenzoic acid $>$ ferulic acid $>$ vanillic acid $>p$-coumaric acid ${ }^{81,83)}$. Corn silk is rich in phenolic compounds, particularly flavonoids and tannins ${ }^{84,85)}$. Flavanols and tannins have a variety of phenolic hydroxyl groups and exhibit the greatest antioxidant ability and free radical-scavenging activity among about one hundred of phenolics $^{81,86,87)}$.

\subsection{Impact of storage time on oxidation stability of neem oil biodiesel}

Oxidation stability is an important biodiesel fuel quality parameter. It is expressed by the induction period(IP). IP can be defined as the length of time before the rapid acceleration of oxidation. It is the measure of resistance to oxidation. The induction period is also known as the oxidative stability index. Generally, every fuel has its own induction period. Based on several studies using the Rancimat test at various temperatures, the induction period is a linear function of the test temperature ${ }^{88,89)}$. In order to avoid degradation, the biodiesel must be stored at a low temperature for a long storage time ${ }^{29)}$. Figure 5 shows the changes in oxidation stability of neem oil biodiesel with and without antioxidants during storage at $25^{\circ} \mathrm{C}$ for 6 months. Generally, oxidation stability values of all biodiesel samples were gradually and significantly $(p \leq 0.05)$ decreased with increasing storage period. This means that the relationship 


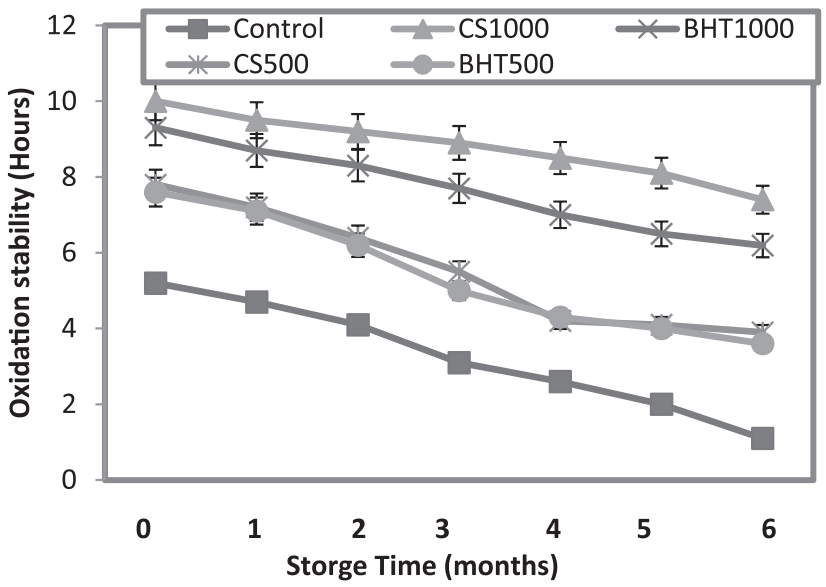

Fig. 5 Changes in the oxidation stability of biodiesel samples treated with different concentration (ppm) of BHT and CSE during storage at room temperature. LSD at $0.05=0.15$.

Data are expressed as mean $\pm \mathrm{SD}$.

Values given represent means of three determinations.

between oxidation stability and storage time is inversely proportional, and the slope of the graph dropped. The highest decreases were observed for control samples (without additives). However, the rates of decrease in oxidation stability are slower for those biodiesel samples blended with different concentrations of antioxidants. At the end of storage time the induction period of treated samples ranged from 3.6 to $7.4 \mathrm{~h}$. These findings indicate that biodiesel samples blended with antioxidants at the end of storage time met the standard ASTM D6751 (3 h) specification, but only biodiesel samples mixed with 1000 ppm of BHT or CSE met the EN 14214(6 h) specification. Here again, at the end of storage period the induction time of biodiesel samples mixed with 1000 ppm of corm silk extract or BHT were about 6.72 and 5.63 times as high as in biodiesel samples without antioxidants. A similar trend has been reported in the oxidation stability of biodiesel ${ }^{79)}$ over an 8 -week storage period. The impact of antioxidant concentration on autoxidation rates depends upon several factors, e.g. antioxidant structure, storage conditions, as well as the composition of the sample being oxidized ${ }^{37)}$. Treatment with oxidation inhibitors is a promising way because it facilitates the use of existing storage tanks and fuel handling systems without requiring upgrades or redesign. Antioxidants such as butylated hydroxytoluene(BHT) or tert-butylhydroquinone (TBHQ) are known to retard effects of oxidation on $\mathrm{AV}$ and $\mathrm{PV}$ of biodiesel ${ }^{90)}$. Other antioxidants known to enhance resistance to oxidation of vegetable oils include, tocopherols, ascorbyl palmitate, butylated hydroxyanisole(BHA) as well as propyl gallate $(\mathrm{PrG})^{91)}$. Oxidation may be interrupted by several types of antioxidants which can react with either chain-carrying peroxyl radicals or the alkyl radical intermediates ${ }^{92)}$. The first class of antioxidants $(\mathrm{AH})$, called primary antioxidants, includes hindered phenols such as butylated hydroxyanisole, butylated hydroxytoluene as well as $\alpha$-tocopherol. To be effective, these compounds must compete with the unsaturated lipid substrate which is normally present in the highest concentration. The second class of antioxidants $\left(\mathrm{Q}^{*}\right)$, called secondary antioxidants, includes quinones such as $\alpha$-tocopherolquinone and ubiquinone which must compete with $\mathrm{O}_{2}$ in a fast reaction. These compounds may therefore only be active in biological systems in which the oxygen content is relatively low ${ }^{93)}$.

\subsection{Impact of storage time on acid value of neem oil bio- diesel}

The oxidation process produces hydroperoxides, aldehydes, ketones, and acids that change the fuel's properties. Therefore, the acid value should be monitored, and fuelenhancing additives may need to be added. Acid value is defined as the mass of potassium hydroxide $(\mathrm{KOH})$ (milligram) that is required to neutralize one gram of a chemical substance. It is also called the acidity number. Generally, the acid value describes the amount of acid in the oil. There are many factors that influence the value of acidity, such as the temperature, storage time, and so forth. Figure 6 shows the changes in acid value of neem oil biodiesel with and without antioxidants during storage at $25^{\circ} \mathrm{C}$ for 6 months. The acid value of neem biodiesel initially was 0.17 mg KOH/g. The results presented in Fig. 6 showed that the acid values of all biodiesel samples under investigation were significantly and gradually increased $(p \leq 0.05)$ with increasing the storage time. Acid can be formed through the oxidation reaction and hydrolysis reaction when exposed to oxygen and moisture in the air, respectively.

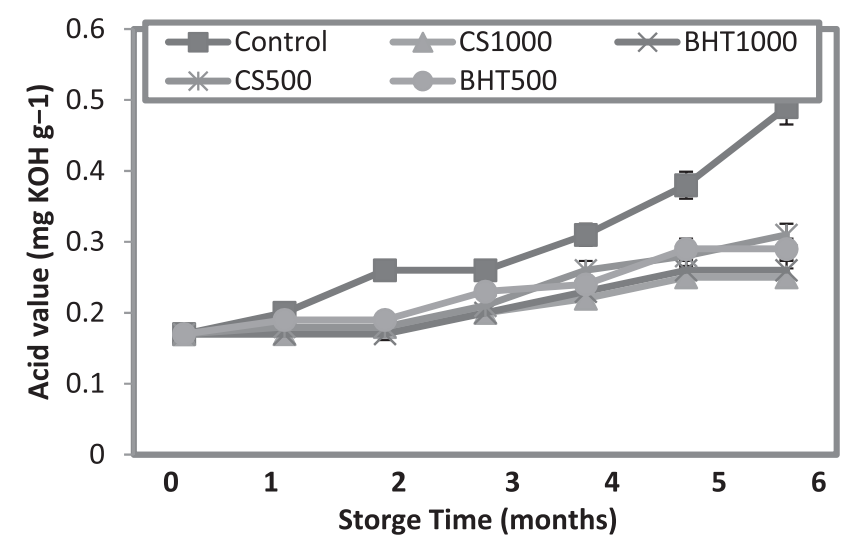

Fig. 6 Changes in acid value of biodiesel samples treated with different concentration (ppm) of BHT and CSE during storage at room temperature.

LSD at $0.05=0.013$

Data are expressed as mean \pm SD.

Values given represent means of three determinations. 
Furthermore, water in oil itself can cause hydrolysis of the esters and turn it into alcohol and acids ${ }^{26,94)}$. The highest level of acidity at the end of storage period $(0.49 \mathrm{mg} \mathrm{KOH} /$ g) was recorded for biodiesel samples which were stored without antioxidants. Biodiesel samples blended with various levels antioxidants had lower levels of acidity at the end of storage time, ranging from 0.25 to $0.31 \mathrm{mg} \mathrm{KOH} / \mathrm{g}$ oil. In the same time, these values were significantly $(p \leq$ 0.05) less than the maximum allowed value of EN 14214 and ASTM D6751 specifications. Mixing biodiesel samples with different concentrations of CSE or BHT led to a significant $(p<0.05)$ decrease in acid values during the storage process. Acid value of biodiesel sample without antioxidants was about 1.68, 1.58, 1.88 and 1.96 times as high as in biodiesel samples mixed with 500ppm BHT, 500 ppm CSE, 1000 ppm BHT and 1000 ppm of CSE, respectively. This finding indicates that the highest reductions of FFA content were observed for biodiesel samples treated with 1000 ppm of BHT or CSE. Corn silk extract has high levels of phenolic compounds and flavonoids (Table 1). Flavonoids are the most common and widely distributed group of phenolic compounds, occurring in corn silk parts. The mechanisms of the actions of flavonoids are through scavenging or chelating processe ${ }^{95,96)}$. Polyphenols include many classes of compounds (phenolic acids, flavanols, xanthones, kaempferol etc.) and act as free radical scavengers. Flavonoid which is the major class of polyphenols exhibits strong antioxidant capacities ${ }^{97)}$. In this respect, Five flavones glycosides (i.e., 2" -O- $\alpha$-l-rhamnosyl-6-C-3" deoxyglucosyl-3'-methoxyluteolin, ax-5'-methane-3'- methoxymaysin, ax-4" -OH-3'-methoxymaysin, 6,4'-dihydroxy-3' methoxyflavone-7-O-glucoside, and 7,4'-dihydroxy- 3'methoxyflavone-2" -O- $\alpha$-l-rhamnosyl-6-C-fucoside) have been successfully isolated from corn silk and identified by Ren et $a l .{ }^{98)}$. They noted that most of the flavones glycosides showed a high antioxidant activity in a lecithin liposome system, as well as a strong scavenging activity against radicals such as 1, 1-diphenyl-2-picrylhydrazyl (DPPH), superoxide, and hydroxyl radicals.

\subsection{Impact of storage time on peroxide value of neem oil biodiesel}

The peroxide value (PV) is an indicator of the state of primary oxidation ${ }^{99)}$. The PV determination measures the presence of oxidative moieties in a sample. The oxidative moieties typically found in biodiesel are hydroperoxides formed when oxygen of air reacts with fatty esters. This usually is the first step in the oxidative degradation process of biodiese ${ }^{100)}$. Peroxide values indicate the extent of intermediate hydroperoxide formation and are expressed as milliequivalents of active oxygen per kilogram of biodiesel sample. Figure 7 shows the changes of peroxide values of neem oil biodiesel with and without antioxidants during storage at $25^{\circ} \mathrm{C}$ for 6 months. The peroxide value of fresh biodiesel without antioxidant (control)was $2.4 \mathrm{meq} / \mathrm{kg}$ oil. A gradual increase in peroxide values as a function of storage time was observed for all biodiesel samples and at all intervals (Fig. 7). This is attributed to the fact that the double bonds in the fatty acid esters are present in methylene-interrupted configuration rather than conjugated structures. The bis-allylic hydrogen in these structures is susceptible to abstraction by free radicals, which renders the molecule reactive with elemental oxygen. Peroxyl radicals formed from reaction with oxygen abstract hydrogen from the bis-allylic site of other polyunsaturated esters, forming hydroperoxides and additional radical esters that propagate a chain reaction, or react with an ester radical to form peroxylinked dimers. The peroxides formed are relatively unstable and react intramolecularly, cleaving the compound adjacent to the double bond into lower molecular weight radicals that then form acids, aldehydes, ketones, alcohols, olefins, and alkanes ${ }^{101)}$. The highest value of peroxide at the end of storage period was observed for antioxidant-free biodiesel. It was observed that the increase in PV of control sample without antioxidants was from $2.4 \mathrm{meq} / \mathrm{kg}$ to $38.45 \mathrm{meq} / \mathrm{kg}$ during the 6 months of storage. The peroxide values at the end of storage time were significantly $(p<0.05)$ lower in biodiesel samples containing antioxidants than in control sample without antioxidants. Blending biodiesel samples with different concentrations of CSE or BHT resulted in a marked decline of their $\mathrm{PV}$ values during storage process, thus showing enhancement of the oxidative stability of neem biodiesel. Peroxide value of biodiesel samples containing 500ppm BHT, 500 ppm CSE, 1000 ppm BHT and 1000 ppm of CSE were about 2.59, 2.51, 4.10 and 4.28 times as low as in control

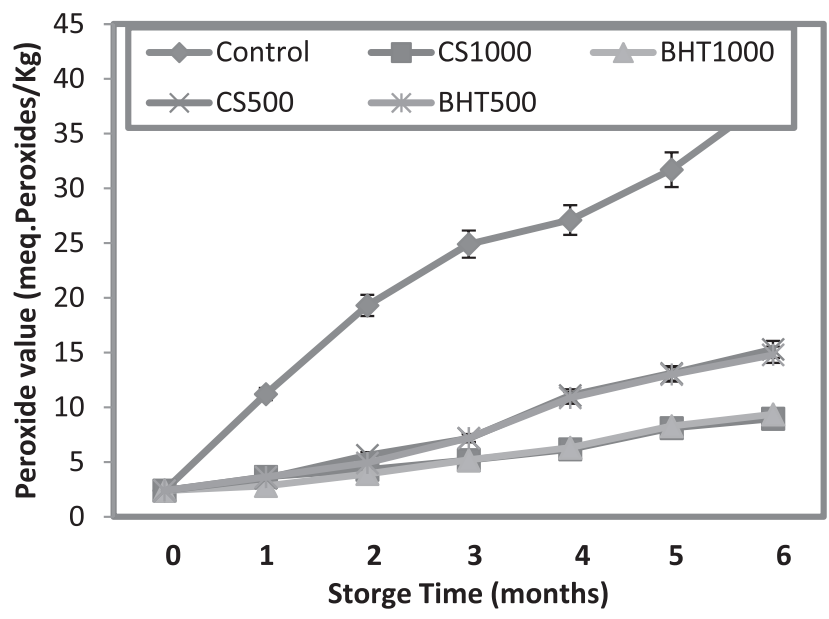

Fig. 7 Changes in peroxide value of biodiesel samples treated with different concentration (ppm) of BHT and CSE during storage at room temperature. LSD at $0.05=0.13$

Data are expressed as mean \pm SD.

Values given represent means of three determinations. 
sample without antioxidants . The inhibition of lipid peroxidation by antioxidants may be due to their free radicalscavenging activities ${ }^{23)}$. The storage stability of biodiesel was first studied by DuPlessis et $a l .{ }^{102)}$, who monitored the production of acids, peroxides, and aldehydes, as well as increase in viscosity and decline in Rancimat induction time over a period of 90 days. They found that exposure to heat and air greatly accelerated degradation of biodiesel, but when stored at $20^{\circ} \mathrm{C}$ in closed containers or stored after the addition of an antioxidant, the biodiesel remained stable.

\section{Conflict of Interests}

None of the authors have any competing interests.

\section{References}

1) Gui, M.M.; Lee, K.T.; Bhatia, S. Feasibility of edible oil vs. non-edible oil vs. waste edible oil as biodiesel feedstock. Energy 33, 1646-1653(2008).

2) Anonymous. Food and Agriculture Organization of the United Nations (FAO). The market and food security implications of the development of biofuel production. FAO committee on commodity problems, sixty-seventh session, Rome, April 20-22 (2009).

3) Nahed, A.; Ghada, M.M.; Ismaiel, H.H.; Hashish, A.S.; Enaam, S.H.; Mohamed, A. Physical and chemical characteristics of neem oils extracted from seed, whole fruit and flesh. Egypt. J. Agric. Res. 93, 887899 (2015).

4) Information unit -Central Administration for Agricultural Extension 2015. Infounit@caae-eg.com/neem trees.

5) Isah, A.B.; Ibrahim, Y.K.; Iwalewa, E.O. Evaluation of the antimalarial properties and standardization of tablets of Azadirachta indica (Meliaceae) in mice. Phytother. Res. 17, 807-810(2003).

6) Badam, L.; Joshi, S.P.; Bedekar, S.S. In vitro antiviral activity of neem (Azadirachta indica, A. Juss) leaf extract against group B Coxsackie viruses. J. Commun. Dis. 31, 79-90(1999).

7) Puri, H.S. Neem-The Divine Tree. Harwood Academic Publishers, Amsterdam (1999).

8) Ragasa, C.Y.; Nacpil, Z.D.; Natividad, G.M.; Tada, M.; Coll, J.C.; Rideout, J.A. Tetranortriterpenoids from Azadirachta indica. J. Phytochem. 46, 555-558 (1997).

9) Johnson, S.; Morgan, E.D.; Peiris, C.N. Development of the major triterpenoids and oil in the fruit and seeds of neem (Azadirachta indica). Ann. Bot. 78, 383-388(1996).
10) Rukmini, C. Chemical and nutritional evaluation of neem oil. Food Chem. 26, 119-124(1987).

11) Jain, S.; Sharma, M.P. Thermal stability of biodiesel and its blends: a review. Renew. Sust. Energ. Rev. 15, 438-448 (2011).

12) Monyem, A.; Van Gerpen, J.H. The effect of biodiesel oxidation on engine performance and emissions. Biomass Bioenergy 20, 317-325 (2001).

13) Sorate, K.A.; Bhale, P.V. Impact of biodiesel on fuel system materials durability. J. Sci. Ind. Res. 72, 48-57 (2013).

14) Shah, R.; Mahajan, D.; Patel, S.; Ball, J.; Colantuoni, V.; Maraj, R. Oxidation stability in biodiesel: a brief review of current technology. Biodiesel Mag. July (2009).

15) Fang, H.L.; McCormick, R.L. Spectroscopic study of biodiesel degradation pathways. SAE Technical Paper 2006-01-3300 (2006).

16） Osawa,W.O.; Sahoo, P.K.; Onyari, J.M.; Mulaa, F.J. Effects of antioxidants on oxidation and storage stability of Croton megalocarpus bioodiesel. Int. J. Energy Environ. Eng. 7, 85-91(2016).

17) Sendzikiene, E.; Makareviciene, V.; Janulis, P. Oxidation stability of biodiesel fuel produced from fatty wastes. Polish J. Environ. Stud. 14, 335-339 (2005).

18）Kähkönen, M.P.; Hopia, A.I.; Vuorela, H.J.; Rauha, J.P.; Pihlaja, K.; Kujala, T.S.; Heinonen, M. Antioxidant activity of plant extracts containing phenolic compounds. J. Agric. Food Chem. 47, 3954-3962 (1999).

19) Ramarathnam, N.; Ochi, H.; Takeuchi, M. Antioxidant defense system in vegetable extracts. In Natural Antioxidants: Chemistry, Health Effects, and Applications. (Shahidi, F. ed.) AOCS Press, Champaign, IL pp. 76-87 (1997).

20) Ramessar, K.; Sabalza, M.; Capell, T.; Christou, P. Maize plants: an ideal production platform for effective and safe molecular pharming. Plant Sci. 174, 409-419 (2008).

21) Velazquez, D.V.O.; Xavier, H.S.; Batista, J.E.M.; de Castro-Chaves, C. Zea mays L. Extracts modify glomerular function and potassium urinary excretion in conscious rats. Phytomedicine 12, 363-369 (2005).

22) Nurhanan A.R.; Rosli, W.I.W. Nutritional compositions and antioxidative capacity of the silk obtained from immature and mature corn. J. King Saud University-Sci. 26, 119-127 (2014).

23) Ebrahimzadeh, M.; Pourmorad, F.; Hafezi, S. Antioxidant activities of Iranian corn silk. Turk. J. Biol. 32, 43-49 (2008).

24) Nurhanan, A.R.; Rosli, W.I.W.; Mohsin, S.S.J. Total polyphenol content and free radical scavenging activity of Cornsilk (Zea mays hairs). Sains Malaysiana 41, 1217-1221 (2012). 
25) Bligh, E.G.; Dyer,W.J. A rapid method of total lipid extraction and purification. Can. J. Biochem. Physiol. 37, 911-917(1959).

26) Ismail, S.A.A.; Ali, R.F.M. Physico-chemical properties of biodiesel manufactured from waste frying oil using domestic adsorbents. Sci. Tech. Adv. Mater. 16, 034602 (2015).

27) Ali, R.F.M.; El Anany, A.M. Recovery of used frying sunflower oil with sugar cane industry waste and hot water. J. Food Sci. Technol. 51, 3002-3013(2014).

28) Saengprachum, N.; Poothongkam, J.; Pengprecha, S. Glycerin removal in biodiesel purification process by adsorbent from rice husk. Int. J. Sci. Eng. Technol. 2, 474-478 (2013).

29) Ashraful, A.M.; Masjuki, H.H.; Kalam, M.A.; Ashrafur Rahman, S M.; Habibullah, M.; Syazwan, M. Study of the effect of storage time on the oxidation and thermal stability of various biodiesels and their blends. Energy Fuels 28, 1081-1089 (2014).

30) Kim, D.-O.; Jeond, S.W.; Lee, C.Y. Antioxidant capacity of phenolic phytochemicals from various cultivars of plums. Food Chem. 81, 321-326 (2003).

31) Fouad, A.A.; Rehab, F.M.A. Effect of germination time on proximate analysis, bioactive compounds and antioxidant activity of lentil(Lens culinaris Medik.) sprouts. Acta Sci. Pol. Technol. Aliment. 14, 233246 (2015).

32) Juntachote, T.; Berghofer, E. Antioxidative, properties and stability of ethanolic extracts of Holy Basil and Galangal. Food Chem. 92, 193-202(2005).

33) Chou, H.J.; Kuo, J.T.; Lin, E.S. Comparative antioxidant properties of water extracts from different parts of beefsteak plant (Perillafrutescens). J. Food Drug Anal. 17, 489-496 (2009).

34) AOCS. Official Methods and Recommended Practices of the AOCS, 5th ed. AOCS Press, Champaign, Illinois (1997).

35) AOAC. Official Methods of Analysis of the Association of Official Analytical Chemists, 17th ed. (Horwitz, W. ed.). Washington, DC (2000).

36) Gomez, K.A.; Gomez, A.A. Statistical Procedures for Agricultural Research. 2nd Edn., IRRI, New York, ISBN-10: 0471879312, p. 680 (1984).

37) Shahidi, F.; Wanasundara, P.K. Phenolic antioxidants. Crit. Rev. Food Sci. Nutr. 32, 67-103(1992).

38) Awika, J.M.; Rooney, L.W.; Wu, X.; Prior, R.L.; Cisneros-Zevallos, L. Screening methods to measure antioxidant activity of sorghum (Sorghum bicolor) and sorghum products. J. Agric. Food Chem. 51, 6657-6662 (2003).

39) Tian, J.; Chen, H.; Chen, S.; Xing, L.; Wang, Y.; Wang, J. Comparative studies on the constituents, antioxidant and anticancer activities of extracts from different varieties of corn silk. Food Funct. 4, 1526-1534
(2013).

40) Xu, B.J.; Chang, S.K. A comparative study on phenolic profiles and antioxidant activities of legumes as affected by extraction solvents. J. Food Sci. 72, S159-166 (2007).

41) Gao, H.; Cheng, N.; Zhou, J.; Wang, B.; Deng , J.; Cao, W. Antioxidant activities and phenolic compounds of date plum persimmon(Diospyros lotus L.) fruits. $J$. Food Sci. Technol. 51, 950-956 (2014).

42) Garcia-Salas, P.; Morales-Soto, A.; Segura-Carretero, A.; Fernández-Gutiérrez, A. Phenolic-compound-extraction systems for fruit and vegetable samples. Molecules 15, 8813-8826 (2010).

43) Musa, K.H.; Abdullah, A.; Jusoh, K.; Subramaniam, V. Antioxidant activity of pink-flesh guava (Psidium guajava L.): effect of extraction techniques and solvents. Food Anal. Method. 4, 100-107(2011).

44) Ghasemzadeh, R.; Nikparast, Y.; Hejri, Z.; Koohestanian, K. Experimental and kinetic study of zero-valent iron nanoparticles performance for the removal of chromium from oil industry waste water. J. Appl. Environ. Biol. Sci. 5, 31-39(2015).

45) Agbangnan, P.C.; Tachon, D.C.; Dangou, J.; Chrostowska, A.; Fouquet, E.; Sohounhloue, D.C.K. Optimization of the extraction of sorghum's polyphenols for industrial production by membrane processes. Res. J. Res. Sci. 1, 1-8(2012).

46) Verma, B.; Hucl, P.; Chibbar, R.N. Phenolic content and antioxidant properties of bran in 51 wheat cultivars. Cereal Chem. 5, 544-549(2008).

47) Meneses, N.G.T.; Martins, S.; Teixeira, J.A.; Mussatto, S.I. Influence of extraction solvents on the recovery of antioxidant phenolic compounds from brewer's spent grains. Sep. Purif. Technol. 108, 152-158 (2013).

48) Prior, R.L.; Lazarus, S.A.; Cao, G.; Muccitelli, H.; Hammerstone, J.F. Identification of procyanidins and anthocyanins in blueberries and cranberries (Vaccinium spp.) using highperformance liquid chromatography/mass spectrometry. J. Agric. Food Chem. 49, 1270-1276 (2001).

49) Guyot, S.; Marnet, N.; Drilleau, J. Thiolysis-HPLC characterization of apple procyanidins covering a large range of polymerization states. J. Agric. Food Chem. 49, 14-20 (2001).

50) Labarbe, B.; Cheynier, V.; Brossaud, F.; Souquet, J.M.; Moutounet, M. Quantitative fractionation of grape proanthocyanidins according to their degree of polymerization. J. Agric. Food Chem. 47, 2719-2723 (1999).

51) Chanda, S.V.; Kaneria, M. J. Optimization of conditions for the extraction of antioxidants from leaves of Syzygium cumini L. using different solvents. Food Anal. Method. 5, 332-338(2012). 
52) Kallithraka, S.; Garcia-Viguera, C.; Bridle, P.; Bakker, J. Survey of solvents for the extraction of grape seed phenolics. Phytochem. Anal. 6, 265-267(1995).

53) Imeh, U.; Khokhar, S. Distribution of conjugated and free phenols in fruits: antioxidant activity and cultivar variations. J. Agric. Food Chem. 50, 6301-6306 (2002).

54) Lee, J.C.; Kim, H.R.; Kim, J.; Jang, Y.S. Antioxidant activity of ethanol extract of the stem of Opuntia ficus-indica var. saboten. J. Agric. Food Chem. 50, 6490-6496 (2002).

55) Ningappa, M.B.; Dinesha, R.; Srinivas, L. Antioxidant and free radical scavenging activities of polyphenolenriched curry leaf (Murraya koenigii L.) extracts. Food Chem. 106, 720-728(2008).

56) Anwar, F.; Qayyum, H.M.A.; Hussain, A.I.; Iqbal, S. Antioxidant activity of $100 \%$ and $80 \%$ methanol extracts from barley seeds (Hordeum vulgare L.): stabilization of sunflower oil. Grasas Aceites 61, 237243 (2010).

57) Stansby, M.E. Fish oils: Their chemistry, technology, stability, nutritional properties and uses. The Avi Publishing Company, Inc. Westport (1967).

58) Markley, K.S. Fatty acids. Their chemistry, properties, production, and uses. Second completely revised and augmented edition. Interscience Publishers, Inc. New York (1961).

59) Shimada, K.; Fujikawa, K.; Yahara, K.; Nakamura, T. Antioxidative properties of xanthone on the auto oxidation of soybean in cylcodextrin emulsion. J. Agr. Food Chem. 40, 945-948(1992).

60) Fukumoto, L.R.; Mazza, G. Assessing antioxidant and prooxidant activities of phenolic compounds. $J$. Agric. Food Chem. 48, 3597-3604(2000).

61) Meyer, A.S.; Jepsen, S.M.; Sorensen, N.S. Enzymatic release of antioxidants for human low-density lipoprotein from grape pomace. J. Agric. Food Chem. 46, 2439-2446 (1998).

62) Sultana, B.; Anwar, F.; Ashraf, M. Effect of extraction solvent/technique on the antioxidant activity of selected medicinal plant extracts. Molecules 14, $2167-$ 2180 (2009).

63) Anwar, F.; Jamil, A.; Iqbal, S.; Sheikh, M.A. Antioxidant activity of various plant extracts under ambient and accelerated storage of sunflower oil. Grasas Aceites 57, 189-197(2006).

64) Sultana, B.; Anwar, F. Flavonols (kaempferol, quercetin, myricetin) contents of selected fruits, vegetables and medicinal plants. Food Chem. 108, 879-884 (2008).

65) Tomsone, L.; Kruma, Z.; Galoburda, R. Comparison of different solvents and extraction methods for isolation of phenolic compounds from horseradish roots (Armoracia rusticana). World Acad. Sci. Eng.
Technol. 64, 903-908(2012).

66) Yildirim, A.; Mavi, A.; Oktay, M.; Kara, A.A.; Algur, O.F.; Bilaloglu, V. Comparison of antioxidant and antimicrobial activities of tilia (Tilia arentea Desf. Ex. D.C.) sage (Salvia triloba L.) and black tea (Camellia sinensis L.) extracts. J. Agr. Food Chem. 48, 5030$5034(2000)$.

67) Jayaprakasha, G.K.; Selvi, T., Sakariah, K.K. Antibacterial and antioxidant activities of grape (Vitis vinisfera) seed extracts. Food Res. Int. 36, 117-122 (2003).

68) Duh, P.D. Antioxidant activity of Budrock (Arctium lappa Linn): its scavenging effect on free radical and active oxygen. J. Am. Oil Chem. Soc. 75, 455-461 (1998).

69) Gordon, M. The mechanism of antioxidant action in vitro. Food antioxidants: Springer, pp. 1-18(1990).

70) Naczk, M.; Shahidi, F. Review: Extraction and analysis of phenolics in food. J. Chromatogr. A 1054, 95111 (2004).

71) Bhaigyaba, T.; Kirithika, T.; Ramya, J.; Usha, K. Phytochemical constituent and antioxidant activity of various extracts of corn silk (Zea mays L.). Res. J. Pharmaceut. Biol. Chem. Sci. 2, 986-993(2011).

72) Alam, E.A. Evaluation of antioxidant and antibacterial activities of Egyptian Maydis stigma (Zea mays hairs) rich in some bioactive constituents. J. Am. Sci. 7, 726-729 (2011).

73) Sahar, A.A.; Mohamed, M.M.; Nematalla Kh.M. Effect of corn silk on characteristics and keeping quality of cake. J. Biol. Chem. Environ. Sci. 7, 371-400 (2012).

74) ASTM 2003 ASTM D6751-08: Standard specification for biodiesel fuel(B100) blend stock for distillate fuels Annual Book of ASTM Standards (West Conshohocken, PA: ASTM International).

75) Van Gerpen, J. Biodiesel processing and production. Fuel Process. Technol. 86, 1097-1107(2005).

76) Dzida, M.; Prusakiewicz, P. The effect of temperature and pressure on the physicochemical properties of petroleum diesel oil and biodiesel fuel. Fuel 87, 1941-1948(2008).

77) ASTM D 6751 - 07, Standard Specification for Biodiesel Fuel Blend Stock(B100) for Middle Distillate Fuels. Philadelphia (2007).

78) EN 14112, Determination of oxidation stability (accelerated oxidation test) (2003).

79) Osawa, W.O.; Sahoo, P.K.; Onyari, J.M.; Mulaa, F.J. Experimental investigation on performance, emission and combustion characteristics of Croton megalocarpus biodiesel blends in a direct injection diesel engine. Int. J. Sci. Technol. 4, 26-33(2015).

80) Roginsky, V. Chain-breaking antioxidant activity of natural polyphenols as determined during the chain 
oxidation of methyl linoleate in triton X-100 micelles. Arch. Biochem. Biophys. 414, 261-270(2003).

81) Rice-Evans, C.A.; Miller, N.J.; Paganga, G. Structureantioxidant activity relationships of flavonoids and phenolic acids. Free Radic. Biol. Med. 20, 933-956 (1996).

82) Kakkar, S.; Bais, S. A review on protocatechuic acid and its pharmacological potential. ISRN Pharmacol. 2014 ID 952943 (2014).

83) Li, W.; Hydanmaka, A.W.; Lowry, L.; Beta, T. Comparison of antioxidant capacity and phenolic compounds of berries, chokecherry and seabuckthorn. Cent. Eur. J. Biol. 4, 499-506 (2009).

84) Liu, J.; Lin, S.; Wang, Z.; Wang, C.; Wang, E.; Zhang, Y.; Liu, J. Supercritical fluid extraction of flavonoids from Maydis stigma and its nitrite-scavenging ability. Food Bioprod. Process. 89, 333-339(2011).

85) Khairunnisa H.; Puziah, H.; Shuhaimi M. Corn silk (Stigma maydis) in healthcare: a phytochemical and pharmacological review. Molecules 17, 9697-9715 (2012).

86) Chun, O.K.; Kim, D.; Lee, C.Y. Superoxide radical scavenging activity of the major polyphenols in fresh plums. J. Agric. Food Chem. 51, 8067-8072(2003).

87) Cai, Y.Z.; Luo, Q.; Sun, M.; Corke, H. Antioxidant activity and phenolic compounds of 112 traditional Chinese medicinal plants associated with anticancer. Life Sci. 74, 2157-2184(2004).

88) Jebe, T.A.; Matlock, M.G.; Sleeter, R.T. Collaborative study of the oil stability index analysis. J. Am. Oil Chem. Soc. 70, 1055-1061 (1993).

89) Xin, J.; Imahara, H.; Saka, S. Kinetics on the oxidation of biodiesel stabilized with antioxidant. Fuel 88, 282-286 (2009).

90) Dunn, R.O. Effect of antioxidants on the oxidative stability of methyl soyate(biodiesel). Fuel Process. Technol. 86, 1071-1085(2005).

91) Pratt, D.E. in: Hui, Y.H. ed., Bailey's Industrial oil and fat products, 5th ed. Edible oil and fat products: Products and application technology, vol. 3, Wiley In- terscience, New York, pp. 412-420 (1996).

92) Haseeb, A.; Masjuki, H.; Ann, L.; Fazal, M. Corrosion characteristics of copper and leaded bronze in palm biodiesel. Fuel Process. Technol. 91, 329-334 (2010).

93) Wanasundra, P. K. J. P. D.; Shahidi, F. In Bailey's Industrial oil and fat products, vol. 1; Shahidi, F., ed.; Wiley Interscience, New York Ch. 11 (2005).

94) Udomsap, P.; Chollacoop, N.; Topaiboul, S.; Hirotsu, T. Effect of antioxidants on the oxidative stability of waste cooking oil based biodiesel under different storage conditions. Int. J. Renew. Energy 4, 47-59 (2009).

95) Kessler, M.; Ubeaud, G; Jung, L. Anti- and pro-oxidant activity of rutin and quercetin derivatives. $J$. Pharm. Pharmacol. 55, 131-142,(2003).

96) Cook, N.C.; Samman, S. Flavonoids-chemistry, metabolism, cardioprotective effects, and dietary sources. J. Nutr. Biochem. 7, 66-76(1996).

97) Fraga, C.G.; Oteiza, P.I. Dietary flavonoids: role of (-) epicatechin and related procyanidins in cell signaling. Free Radic. Biol. Med. 51, 813-823(2011).

98) Ren, S.H.; Qiao, Q.Q.; Ding, X.L. Antioxidative activity of five flavones glycosides from corn silk (Stigma maydis). Czech. J. Food Sci. 2, 148-155(2013).

99) Augustin, M.A.; Berry, S.K. Effectiveness of antioxidants in refined, bleached and deodorized palm olein. J. Am. Oil Chem. Soc. 60, 105-108(1983).

100) Frankel, E.N. Lipid Oxidation 2nd ed. (Barnes, P.J. and associates eds.) The Oily Press, Bridgewater, England (2005).

101) Chuck, C.J.; Jenkins, R.W.; Bannister, C.D.; Han, L.; Lowe, J.P. Design and preliminary results of an NMR tube reactor to study oxidative degradation of fatty acid methyl ester. Biomass Bioenergy 47, 188-194 (2012).

102) Du Plessis, L.M.; De Villiers, J.B.M.; Van Der Walt, W.H. Stability studies on methyl and ethyl fatty acid esters of sunflower seed oil. J. Am. Oil Chem. Soc. 62, 748-752(1985). 